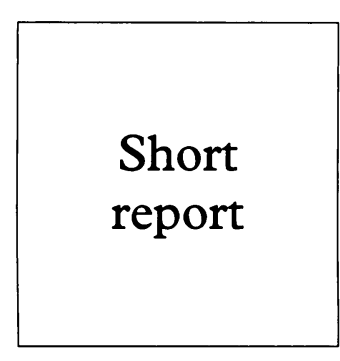

\section{Sexual risk behaviour among subgroups of heterosexual HIV infected patients in an urban setting}

Jack A DeHovitz, Joseph Feldman, Lawrence S Brown, Howard Minkoff

Objective: To determine the frequency of characteristics associated with unprotected heterosexual intercourse in HIV infected adults in an urban area.

Design: Retrospective comparison of sexual risk transmission behaviour between HIV infected men and women from a drug treatment site and between women from the drug site and HIV infected women from an urban medical centre.

Methods: HIV infected women and men were asked questions on sexual behaviour for a 1 year period before enrolment. The outcome variable was heterosexual risk behaviour (HRB) defined as having vaginal sex at least once in the previous year and not always using condoms.

Results: $73 \%$ of the drug clinic females, $72 \%$ of the drug clinic males, and $42 \%$ of the medical $\stackrel{2}{=}$ centre females engaged in HRB. Using logistic regression analysis, women and men in drug treatment engaged in similar rates of HRB; however, women in drug treatment were four times $(95 \% \mathrm{CI}=2 \cdot 0-8 \cdot 3)$ more likely to engage in HRB risk behaviour than women from the medical centre.

Conclusion: The data suggest that a surprisingly large portion of HIV infected patients under treatment engaged in HRB, especially former drug users. Without specifically targeted interventions, the heterosexual spread of HIV in urban areas will continue to be a serious problem. (Genitourin Med 1997;73:552-554)

Keywords: HIV; sexually transmitted diseases; heterosexual sex; urban health

\section{Introduction}

The scope and direction of the HIV epidemic will be determined, in large part, by risk behaviours of infected and "at risk" populations. Education programmes designed to modify sexual risk behaviour have targeted men who have unprotected sex with men, adolescents, prostitutes, and injecting drug users (IDUs), among others. These programmes have been based on an understanding of the risk behaviours within each group. However, despite an increasing prevalence of HIV among women, the sexual behaviour of HIV infected women in the United States has not been extensively investigated. In this paper, we report on the sexual risk behaviours of 158 HIV infected women treated at an urban medical centre, as well as 131 infected women and 218 infected men being seen at a drug treatment facility in the same community.

Methods
Patients presented in this analysis were
recruited into separate cohort studies of HIV
infected individuals in Brooklyn. One included
women at an urban medical centre, ${ }^{1}$ and the
other both men and women at a drug treat-
ment clinic. ${ }^{2}$ Both the medical centre and the
drug clinic are located within a few miles of
each other, and draw patients from the same
community. Trained interviewers independent
of treatment programmes at both sites
recruited consecutive patients during the time

\section{Methods} and Treatment Corporation, Brooklyn, New York, USA

L S Brown

Correspondence to: Jack A DeHovitz, MD SUNY Health Science Center at Brooklyn Department of Preventive Medicine, 450 Clarkson Avenue, Box 1240 , Brooklyn, NY 11203, USA. Accepted for publication 20 May 1997 that they were assigned to the programme. Subject were reimbursed from $\$ 10$ to $\$ 20$ for their participation. Around $80-90 \%$ of subjects approached agreed to participate. At enrolment, subjects were interviewed using precoded standard questionnaires. The questionnaires used at the drug treatment clinic and the urban medical centre, although not exactly the same, contained several questions (demographics, sex history, drug use) that were the same or were made consistent by regrouping. The questions on sexual behaviour in both cohorts focused on the 1 year period before enrolment. The questionnaire at the medical centre noted the date of women's of HIV tests, and only patients who were infected $\tilde{O}$ for at least 12 months were included in this $\underset{\omega}{N}$ analysis. Although patients from the drug treatment clinic did not report the time of prior HIV tests, at least half had been tested as part of a separate study 1 year before entry into this study. ${ }^{3}$ At the medical centre, women were cultured for Neisseria gonorrhoea, Chlamydia trachomatis, Trichomonas vaginalis, $\underset{\mathbb{D}}{\mathbb{Q}}$ and had serological tests for syphilis. Similar cultures were not available for individuals being seen at the drug treatment facility. Women from the medical centre were enrolled between September 1991 and May 1993. Patients from the drug treatment centre were enrolled from June 1989 to the end of December 1991.

Groups were compared using exact contingency table analysis. ${ }^{4}$ For nominal groups, the 
Table 1 Transmission risk by demographic variables among three groups

\begin{tabular}{|c|c|c|c|c|c|c|c|c|c|}
\hline & \multicolumn{6}{|c|}{ Drug clinic } & \multirow{2}{*}{\multicolumn{2}{|c|}{$\frac{\text { Urban medical centre }}{\text { Female }}$}} & \multirow[b]{3}{*}{$p_{3}$ Value } \\
\hline & \multicolumn{2}{|c|}{ Male } & \multirow[b]{2}{*}{$p_{1}$ Value } & \multicolumn{2}{|c|}{ Female } & \multirow[b]{2}{*}{$p_{2}$ Value } & & & \\
\hline & No & $\% H R B^{*}$ & & No & $\% H R B$ & & No & $\% H R B$ & \\
\hline $\begin{array}{l}\text { Age (years): } \\
<25 \\
25-29 \\
30-34 \\
35-39 \\
40 \dagger\end{array}$ & $\begin{array}{r}4 \\
15 \\
51 \\
73 \\
75 \\
218\end{array}$ & $\begin{array}{l}75 \\
67 \\
77 \\
71 \\
72 \\
72\end{array}$ & 0.53 & $\begin{array}{r}5 \\
15 \\
29 \\
45 \\
37 \\
131\end{array}$ & $\begin{array}{r}100 \\
94 \\
79 \\
78 \\
49 \\
73\end{array}$ & 0.001 & $\begin{array}{r}10 \\
37 \\
49 \\
36 \\
26 \\
158\end{array}$ & $\begin{array}{l}80 \\
54 \\
45 \\
28 \\
27 \\
42\end{array}$ & 0.001 \\
\hline \multirow{3}{*}{$\begin{array}{l}\text { CD4 }\left(\times 10^{6} / 1\right): \\
<200 \\
200-499 \\
500+\end{array}$} & & & ORt $=5 \cdot 5$ & & & $95 \% \mathrm{CI}=3 \cdot 1-9 \cdot 8$ & & & $p=0.001$ \\
\hline & $\begin{array}{l}49 \\
85 \\
63\end{array}$ & $\begin{array}{l}69 \\
73 \\
73\end{array}$ & 0.75 & $\begin{array}{l}23 \\
50 \\
42\end{array}$ & $\begin{array}{l}39 \\
80 \\
79\end{array}$ & 0.002 & $\begin{array}{l}37 \\
82 \\
35\end{array}$ & $\begin{array}{l}38 \\
38 \\
57\end{array}$ & $0 \cdot 12$ \\
\hline & & & $O R=2 \cdot 4$ & & & $95 \% \mathrm{CI}=1 \cdot 5-4 \cdot 0$ & & & $p=0.001$ \\
\hline \multirow[t]{2}{*}{$\begin{array}{l}\text { Income }(\$): \\
\quad<5000 \\
5000-10000 \\
10000+\end{array}$} & $\begin{array}{r}147 \\
51 \\
20\end{array}$ & $\begin{array}{l}68 \\
78 \\
85\end{array}$ & 0.07 & $\begin{array}{r}87 \\
35 \\
9\end{array}$ & $\begin{array}{l}74 \\
69 \\
77\end{array}$ & 0.99 & $\begin{array}{l}24 \\
33 \\
85\end{array}$ & $\begin{array}{l}50 \\
46 \\
35\end{array}$ & 0.66 \\
\hline & & & $\mathrm{OR}=2 \cdot 7$ & & & $95 \% \mathrm{CI}=1 \cdot 5-5 \cdot 1$ & & & $p=0.001$ \\
\hline \multirow{2}{*}{$\begin{array}{l}\text { Education: } \\
\quad 0-11 \\
\quad \geqslant 12\end{array}$} & $\begin{array}{r}121 \\
97\end{array}$ & $\begin{array}{l}71 \\
73\end{array}$ & 0.76 & $\begin{array}{l}87 \\
44\end{array}$ & $\begin{array}{l}72 \\
73\end{array}$ & 0.92 & $\begin{array}{l}82 \\
74\end{array}$ & $\begin{array}{l}48 \\
35\end{array}$ & $0 \cdot 14$ \\
\hline & & & $O R=3.5$ & & & $95 \% \mathrm{CI}=2 \cdot 1-5.9$ & & & $p=0.001$ \\
\hline
\end{tabular}

${ }^{\star} \mathrm{HRB}=$ had sex in past 12 months and did not always use condoms.

tOdds ratio $(O R)=$ the ratio of $\mathrm{HRB}$ in drug clinic female to urban medical centre female adjusted for specific characteristic.

Number of patients may not always equal total because unknowns are excluded.

generalised Fisher's exact test was used. For rank groupings, an exact trend test was used. Multiple logistic regression analysis was used to adjust for potential confounders when comparing groups.

The outcome variable was heterosexual risk behaviour (HRB), which was defined as having vaginal sex at least once in the previous year and not always using condoms.

\section{Results}

Males and females from the drug clinic were of similar age (median 37 years), marital status (one third married), income (two thirds $<\$ 5000,8 \%>\$ 10000)$, and had similar CD4 level (median 400), and similar frequency of weekly vaginal sex in the past year. Males, however, were more likely than females to report three or more partners in the past year $(30 \% v 12 \% ; \mathrm{p}<0.001)$. Females from the medical centre differed from those from the drug clinic in several ways. Women from the medical centre were younger (median 33

Table 2 Characteristics between men and women from drug clinic by transmission risk

\begin{tabular}{|c|c|c|c|c|}
\hline & \multicolumn{2}{|c|}{ Male } & \multicolumn{2}{|c|}{ Female } \\
\hline & No & $\% H R B^{*}$ & No & $\% H R B$ \\
\hline \multicolumn{5}{|c|}{ No of new partners in past year: } \\
\hline 0 & 183 & - & 55 & - \\
\hline 1 & 23 & 70 & 16 & 75 \\
\hline 2 & 35 & 83 & 6 & 100 \\
\hline $3-5$ & 18 & 94 & 5 & 80 \\
\hline $6+$ & 10 & 80 & 3 & 100 \\
\hline \multicolumn{5}{|c|}{ Currently on methadone: } \\
\hline Yes & 74 & 66 & 38 & 61 \\
\hline \multicolumn{5}{|c|}{ Cocaine in urine: } \\
\hline Yes & 24 & 63 & 14 & 45 \\
\hline No & 98 & 66 & 44 & 69 \\
\hline \multicolumn{5}{|c|}{ Change behaviour to reduce risk: } \\
\hline Yes & 147 & 69 & 67 & 73 \\
\hline \multicolumn{5}{|c|}{ No of 1 night stands in past year: } \\
\hline 1 & 13 & 77 & 3 & 100 \\
\hline 2 & 11 & 100 & 3 & 67 \\
\hline 3 & 9 & 67 & 1 & 100 \\
\hline $4-10$ & 16 & 81 & i & 100 \\
\hline $11+$ & 5 & 100 & 4 & 100 \\
\hline
\end{tabular}

${ }^{\star} \mathrm{HRB}=$ had sex in past 12 months and did not always use condoms. years; $\mathrm{p}<0.001)$, of higher income $(60 \%<10000 ; \mathrm{p}<0.001)$ and education $(\mathrm{p}<0.02)$, and were less sexually active $(7 \%$, three partners or more; $\mathrm{p}<0.06)$. Almost $88 \%$ of males and $82 \%$ of females from the drug clinic and $85 \%$ of females from the medical centre had one or more sex partner in the previous year, and almost half of each group reported vaginal intercourse weekly or more. Median CD4 levels were somewhat higher in patients from the drug clinic (400 v 351; $\mathrm{p}<0.05)$. In all, $18 \%$ of women from the medical centre reported infection from intravenous drug use, $75 \%$ from heterosexual transmission, 3\% from blood transfusions, and $4 \%$ unknown.

Table 1 shows the frequency of patients engaging in HRB by demographic variables. Overall, $73 \%$ of drug clinic females and $72 \%$ of males, and $42 \%$ of medical centre females engaged in HRB. Females from the drug clinic were $2 \cdot 5-5 \cdot 5$ times more likely to engage in HRB than medical centre females, adjusting separately for age, CD4, income, and education. At the urban centre, current drug users were 1.62 times more likely ( $p<0.42,95 \%$ CI $0.54-4.94$ ) than non-users to engage in HRB, but only $9.5 \%$ of participants at the urban centre were current drug users, resulting in wide confidence intervals and an insignificant $p$ value.

Among females, HRB decreased with age and declining CD4 level. Among males, there were no consistent trends. Not surprisingly, HRB increased with increased frequency of sex in all groups. In the drug clinic, HRB existed in almost all patients engaging in sex weekly or more in contrast with $56-69 \%$ of those engaging in sex less than monthly $(p<0.001)$. In the medical centre, over half of the females reporting sex weekly or more engaged in HRB compared with only $20 \%$ of those having sex less than monthly $(p<0.001)$. In general, HRB in males and females from the drug clinic was consistent, even among subgroups (table 2 ). In a multiple 
logistic comparison of HRB between males and females from the drug clinic, there was no difference after adjusting for age, income, education, and $\mathrm{CD} 4$ groups $(\mathrm{OR}=1 \cdot 12, \mathrm{p}=$ $0 \cdot 68, \quad 95 \% \quad \mathrm{CI}=0 \cdot 6-2 \cdot 1)$. Conversely, women from the drug clinic were four times $(95 \% \mathrm{CI}=2 \cdot 0-8 \cdot 5)$ more likely to engage in HRB risk behaviour than women from the medical centre, even after adjustment for age, income, education, and CD4 levels in a multiple logistic regression model. Among women from the medical centre, there was a suggestion that those diagnosed with an STD ( $T$ vaginalis, $C$ trachomatis, $N$ gonorrhoeae, or syphilis) more often engaged in HRB risk $(53 \% v 39 \% ; \mathrm{p}<0.14)$, but the difference was not statistically significant. Women from the medical centre whose partners were HIV positive were significantly more likely to have engaged in HRB ( $56 \% v 33 \%$; $p<0.047)$.

\section{Discussion}

The present study indicates HRB is common in all subgroups of HIV infected patients studied. Even among those with the lowest frequency of risk behaviour, women from the urban medical centre whose partners were not HIV infected, one third engaged in HRB. Among patients from a drug clinic, either male or female, almost three quarters engaged in HRB. Women from the medical centre were significantly less likely than women at the drug clinic to engage in HRB, even after adjusting for differences in age, education, income, and disease stage.

One possible reason for the difference in HRB between the two groups of women (urban centre and drug clinic) is the possibility of residual confounding between socioeconomic status and place of treatment. Women from the drug clinic were uniformly of lower income and educational status than women from the medical centre, and even though we adjusted for these factors, the adjustment may not reflect the actual differences in socioeconomic status between the two groups of women. For example, income was available only in broad categories, and over two thirds of the subjects from the drug clinic reported less than $\$ 5000$ compared with only $17 \%$ of women from the urban centre. Another concern is our definition of HRB, which may not be appropriate for women in monogamous relationships with a known HIV infected partner. However, the number of such women is relatively small. Only about $8 \%$ of the cohort knew that their partner was HIV positive. In any event, the accuracy of partner status reports is unknown. Additionally, the advantage of defining risk behaviour, as we have, is that it is a simple index that is comparable across different studies. ${ }^{10}$

There are limitations in an observational study which gathered data using different questionnaires for patients from the different study sites, but only precoded questions gathering the same data were used for analysis. It is also not clear that risk behaviour actually occurred during a period in which all individuals at the drug clinic knew that they were infected. However, most were longstanding drug users, with $98 \%$ having both used drugs intravenously for more than a year before enrolment and received medical care, and risk behaviours in this group are important whether HIV status is known or not. ${ }^{5}$

Finally, the possibility of a cohort effect needs to be acknowledged since the cohorts were enrolled at different times. However, the difference was only 2 years, reducing the likelihood that secular trends might account for the differences.

The demography of HIV infection in the United States is undergoing dramatic shifts with heterosexuals, both drug users and female partners of drug users, comprising an increasing percentage of the infected. The behaviours of HIV infected individuals within those populations will therefore play a critical role in determining the size of the epidemic. Previous work has suggested that consistent condom use in these groups may be low..$^{6-9}$ Our data indicate that those HIV infected patients sufficiently immersed in the drug culture to seek treatment at a drug clinic are at much greater risk of HRB. Unless interventions can be developed which are tailored to this group and which prove to be as effective as those reported among homosexual males, the heterosexual spread of HIV in urban areas will continue to be a serious health problem.

This work was supported by the NIDA grant no DA 05581 , NIAID grant no RO1-AZ-31834, and CONRAD, subproject agreement CS4-94-134.

1 Augenbraun MH, Dehovitz JA, Feldman J, Clarke L Landesman S, Minkoff $\mathrm{H}$. Biological false-positive syphilis test results for women infected with human immunodeficiency virus. Clin Infect Dis 1994;19:1040-4.

2 Battjes RJ, Pickens RW, Brown Jr, LS. HIV infection and AIDS risk between among injecting drug users enterin methadone treatment: an update. F Acquir Immune Defic Syndr 1995;10:90-6.

3 Brown LS, Chu A, Nemoto T, Ajuluchukwu D, Primm BJ Human immunodeficiency virus infection in a cohort of intravenous drug users in New York City. NY State 7 intravenous drug use

4 Catania JA, Coates TJ, Still R, Turner H, Peterson J, Hearst N, et al. Prevalence of AIDS-related risk factors and condom use in the United States. Science 1992; 258:1101-6.

5 Lewis DK, Watters JK. Sexual risk behavior among heterosexual intravenous drug users: ethnic and gender variations. AIDS 1991;5:77-83.

6 Magura S, Kung SK, Shapiro J. Outcomes of intensive AIDS education for male adolescent drug users in jail. $\mathcal{f}$ Adolescent Health 1994;15:457-63.

7 Mehta C, Patel N. StatXact Statistical Software for Exact Non-parametric Inference (vers.2). Cambridge, MA: Cytel Software Corp, 1991.

8 O'Donnell L, San Doval A, Vornfett R, O'Donnell C. STD prevention and the challenge of gender and cultural diversity: knowledge, attitudes and risk behaviors among black and Hispanic inner-city STD clinic patients. Sex Transm Dis 1994;21:137-48.

9 Temmerman M, Ndinya-Achole J, Ambani J, Plot P. The right not to know HIV test results. Lancet 1995;345: 969-70.

10 Singh BK, Koman JJ, Caten UM, Souply KL, Birkel RC, Golaszewski TJ. Sexual risk behavior among injection drug-using human immunodeficiency virus positive clients. Int $\mathcal{F}$ Addict 1993;28:735-47. 